\title{
Task Complexity and Second Language Teaching
}

\author{
GAO Hai-long \\ China Youth University of Political Studies, Beijing, China
}

\begin{abstract}
In the past few years, the notion of task complexity has been receiving substantial attention in the field of second language acquisition. This paper explores task complexity from the cognitive perspective by analyzing two studies with Skehan's limited capacity hypothesis and Robinson's cognition hypothesis. The two studies, namely You-Jin Kim's (2012) and Mirdamadi and Jong (2015), explore on how linguistic complexity affects language performance. Two hypotheses, Skehan's limited capacity hypothesis and Robinson's cognition hypothesis, explain the two studies from the cognitive perspective by predicting either that increasing task complexity reduces a pool of attentional capacity during task performance or that increasing complex tasks promotes greater accuracy and complexity of speech and writing. It is suggested that language teaching, syllabus designing in particular, should be based on the basis of task complexity.
\end{abstract}

Keywords: task complexity, limited capacity hypothesis, cognition hypothesis

\section{Introduction}

In the discussion on language complexity, complexity refers to formal properties of the linguistic system, that is structural complexity, a formal property of texts and linguistic systems having to do with the number of their elements and their relational patterns (Pallotti, 2015). Complexity also refers to something that has to do with issues of cost, difficulty, level of demand for a language learner, that is, cognitive complexity, having to do with the processing costs associated with linguistic structures. A third meaning of complexity in linguistic research is closely related to difficulty and it has to do with how a linguistic structure is acquired by a first or second language learner. Ellis (2009) identifies complexity with "the capacity to use more advanced language", which equates complex structures with structures appearing late in L2 development. In this sense, developmental complexity, i.e., the order in which linguistic structures emerge and are mastered in second and, possibly, first language acquisition is regarded as the difficulty of how language learners learn to use linguistic structures.

In second language studies, the construct of task complexity has to do with exploring how increasing task complexity affects interaction and learning outcomes (Robinson, 2001a, 2007b). Task complexity is relevant to cognitive demands that task designing imposes on language learners, whose operation is a continuum (Skehan, 1998; Robinson, 2001a, 2003). Task-complexity has been operationalized in various ways, including the occurrence of specific feedback types such as recasts and clarification requests and the number of language-related episodes.

This paper analyzes language complexity from a cognitive perspective by reviewing on two studies on task complexity and giving them explanations from cognitive perspective and finally discussing second language teaching syllabus designing on the bases of task complexity.

GAO Hai-long, associate professor, master, English Department, China Youth University of Political Studies. 


\section{Exploring Complexity From a Cognitive Perspective}

Mirdamadi and Jong (2015) note that if a system or linguistic feature needs more cognitive efforts to process, it is cognitively difficult, or relatively complex. In their study, Mirdamadi and Jong (2015) explores on how syntactic complexity affects speaking performance both in first and in second language in terms of oral fluency. Thirty subjects of Dutch native speakers with an average to advanced English level take two speaking experiments, one in Dutch and one in English. The researchers operationalize syntactic complexity by eliciting subjects' use of active and passive sentences. Through comparing syntactic complexity effect on various fluency measures, the results reveal underlying cognitive processes in on-line speech production. Experiment results show that syntactic complexity provokes hesitations, both in Dutch and in English. Besides, the effect of syntactic complexity in second language is found to be larger for first language speech. Lastly, syntactic complexity does not affect articulation rate, either in first language or in second language.

This can be explained from a cognitive perspective. Increased cognitive resources are required while processing second language as less automatized language representations means larger demands of encoding processing at the structural, lexical, and phonological levels. Second language learners might need to build proficiency in both new lexical mappings and phonetic encoding schemes based on the rules of the second language. It is thus predictable that higher second language proficiency leads to more native-like second speech, including faster speaking rates and fewer errors as well as language-specific articulatory patterns (e.g., Flege, Schirru, \& MacKay, 2003). Pausing time in second language speech deceases with increased second language proficiency. Nip and Blumenfeld (2015) predict that producing syntactically complex utterances in second language may further require processing demands of a speaker, for in particular second language learner of lower proficiency.

Also, Skehan's limited capacity hypothesis (1998) predicts that learners' attentional resources are limited and that increasing task complexity reduces a pool of attentional capacity during task performance. Skehan (1998) argues that there is trade-off between attention to form and attention to meaning while performing task. Consequently, more complex tasks demand more attention to meaning and thus allocate less attention to language form. Skehan (1998) also argues that, because attentional resources are limited, second language learners cannot attend to complexity, fluency, and accuracy at the same time. Thus, tasks can promote either increased complexity or accuracy, but not both.

You-Jin Kim's (2012) study examines the effects of task complexity on the occurrence of interaction-driven learning opportunities and question development in classroom context. One hundred and ninety-one Korean college students from four English classes are randomly assigned to one comparison group and three experimental groups with different tasks at different complexity levels, that is simple, + complex, and ++ complex. Results show that more complex tasks promote a greater number of language related episodes which is regarded as the occurrences of learning opportunities identified in the subjects' interactions; and increasing complex tasks, in particular, lead to language related episodes targeting developmentally advanced question structures. And the developmentally advanced question structures lead to question development which is identified between pretest and posttests based on the learners' stage advancement.

This can be explained by Robinson's cognition hypothesis which claims complex tasks should promote greater accuracy and complexity of speech and writing, as well as more interaction, and learning of information 
provided in the input to task performance, than simpler tasks (e.g., Robinson, 2005, 2007b). Robinson's cognition hypothesis states that learners can allocate their attention to multiple aspects of language. There is no trade-off between attention to accuracy and attention to complexity of language production. Rather, increasing task complexity promotes accuracy and complexity in language production. Robinson (2001a, 2001b, 2003) categorizes task complexity into two types: cognitive-conceptual (i.e., resource-directing) and performative-procedural (i.e., resource-dispersing) demands.

Based on a limited-capacity conception of attention and memory, Skehan (1998; Skehan \& Foster, 2001) suggests that when task demands are high, attention can only be allocated to either complexity or accuracy, but not to both simultaneously. Robinson (2001a, 2003) agrees with Skehan when it comes to resource-dispersing features, since increasing complexity along those variable exhausts attention from how the message is being encoded. Nevertheless, Robinson predicts that increasing complexity along resource-directing dimension has the potential to direct learners' attention to both complexity and accuracy.

\section{Task Complexity and Second Language Teaching}

Task complexity varies due to a number of factors. For instance, a task in which low proficiency learners are asked on the spot to describe what they did the day before can be very demanding, since they have to improvise a narrative without previous preparation and by referring to events which are displaced in time and space. In this kind of case, language production can be expected to be affected by such high demands. On the other hand, giving learners time to prepare the narration of a comic strip that they can look at while speaking would considerably reduce the demands that the task imposes on learners, which would have specific consequences for production.

Task complexity has been an important factor in sequencing learning tasks in syllabi in various language teaching approaches. For example, Skehan (1998) suggests that task factors should be considered when designing and sequencing tasks in order to ensure a balanced development in language production. These factors include the task complexity of the language (e.g., the grammatical and lexical complexity of the texts in the tasks), its cognitive complexity (e.g., familiarity with the task or the amount and organization of the information in the task), the communicative stress of the situation (e.g., what is at stake), to which learner factors can be added. Robinson (2001a, 2003) suggests organizing task designing into several factors, including complexity factors (e.g., the number of elements in a task or the time allocated to pre-task planning), interactive factors (e.g., whether information mainly flows from one speaker to another or equally between two speakers), and learner factors such as proficiency. Robinson argues that task complexity factors should be used as a reference for making prospective decisions about syllabus design.

\section{Conclusion}

To conclude, this paper has, based on three meanings of complexity, discussed task complexity in language learning. Based on a limited-capacity conception of attention and memory, Skehan suggests that when task demands are high, attention can only be allocated to either complexity or accuracy, but not to both simultaneously. Robinson agrees with Skehan when it comes to resource-dispersing features, since increasing complexity along those variable exhausts attention from how the message is being encoded. Nevertheless, Robinson predicts that increasing complexity along resource-directing dimension has the potential to direct learners' attention to both complexity and accuracy. These two hypotheses are borrowed to explain two studies 
on task complexity of language learning. These two hypotheses suggest that task complexity be taken as an important factor in sequencing learning tasks in syllabi in language teaching approaches.

\section{References}

Ellis, R. (2009). The differential effects of three types of task planning on the fluency, complexity, and accuracy in L2 oral production. Applied Linguistics, 30, 474-509.

Flege, J. E., Schirru, C., \& MacKay, I. R. A. (2003). Interaction between the native and second language phonetic subsystems. Speech Communication, 40, 467-491. doi:10.1016/S0167-6393(02)00128-0

Kim, Y. J. (2012). Task complexity, learning opportunities, and Korean EFL learners' question development. Studies in Second Language Acquisition, 34, 627-658.

Linck, J. A., Schwieter, J. W., \& Sunderman, G. (2011). Inhibitory control predicts language switching performance in trilingual speech production. Bilingualism: Language and Cognition, 15, 651-662. doi:10.1017/S136672891100054X

Nip, I. S. B., \& Blumenfeld, H. K. (2015). Proficiency and linguistic complexity influence speech motor control and performance in Spanish language. Learners Journal of Speech, Language and Hearing Research (Online), 58(3), 653-668.

Pallotti, G. (2015). A simple view of linguistic complexity. Second Language Research, 31(1), 117-134.

Robinson, P. (2001a). Task complexity, cognitive resources and syllabus design: A triadic framework for examining task influences on SLA. In P. Robinson (Ed.), Cognition and second language instruction (pp. 287-318). New York: Cambridge University Press.

Robinson, P. (2001b). Task complexity, task difficulty, and task production: Exploring interactions in a componential framework. Applied Linguistics, 22, 2-57.

Robinson, P. (2003). The cognition hypothesis, task design, and adult task-based language learning. Second Language Studies, 21, 45-105.

Robinson, P. (2005). Cognitive complexity and task sequencing: Studies in a componential framework for second language task design. International Review of Applied Linguistics in Language Teaching, 43, 1-32.

Robinson, P. (2007a). Criteria for classifying and sequencing pedagogic tasks. In M. P. Garcia-Mayo (Ed.), Investigating tasks in formal language settings (pp. 7-26). Bristol, UK: Multilingual Matters.

Robinson, P. (2007b). Task complexity, theory of mind, and intentional reasoning: Effects on L2 speech production, interaction, uptake and perceptions of task difficulty. International Review of Applied Linguistics in Language Teaching, 45, 193-213.

Skehan, P. (1998). A cognitive approach to language learning. Oxford: Oxford University Press.

Skehan, P. (2003). Task-based language teaching. Language Teaching, 36, 1-14.

Skehan, P., \& Foster, P. (2001). Cognition and tasks. In P. Robinson (Ed.), Cognition and second language instruction (pp. 183-205). New York: Cambridge University Press. 